\title{
Repressão Penal às Violações do Direito de Autor. As Inovações Introduzidas pela Lei N. 6.895, de 17.12.1980, Aumenta- ram as Atribuições dos Delegados de Polícia*
}

\author{
Antônio Chaves \\ Diretor da Faculdade de Direito e Catedrático de \\ Direito Civil da Universidade de São Paulo
}

\begin{abstract}
SUMÁrio: 1 . O direito de autor é um direito natural do homem. Fundamento jurídico de sua proteção civil e penal. 2. No rol das violações ao direito de autor, o papel desempenhado pela contrafação. 3. Atribuiçōes dos Delegados de Policia em matéria de propriedade imaterial. A aprovação prévia dos programas dos espetáculos públicos remunerados. 4. Colaboração das autoridades policiais com o Ministério do Trabalho. 5. O novo texto legislativo é de tamanha importância. 6. Ação penal. A dispensa da formalidade da queixa. 7. Busca e apreensão. Conceito. Vantagens. 8. Aplicabilidade tanto no âmbito civil como no criminal. 9. Tanto no direito de autor como na propriedade industrial. 10. Conseqüências práticas da simplificação. 11. O direito de autor não dispensa a preciosa colaboração das autoridades policiais.
\end{abstract}

\section{O direito de autor é um direito natural do homem. Fundamento jurídico de sua proteção civil e penal}

Reconhece a legislação positiva de todos os países civilizados ao autor o direito exclusivo de reproduzir ou de autorizar a reprodução de suas obras, sempre que haja intuito de obtenção direta ou indireta de lucro.

É uma prerrogativa de tão alta significação que está consagrada na Declaração Universal dos Direitos do Homem, aprovada na III sessão ordinária da Assembléia Geral das Nações Unidas.

* Estudo elaborado em virtude de determinação do Presidente do Conselho Nacional de Direito Autoral, Dr. Jost Clarlos Costa Netto. 
“Art. 27. 1. Toda pessoa tem direito de participar livremente da vida cultural da comunidade, de gozar das artes e de participar do programa científico e dos benefícios que dele advenham.

2. Toda pessoa tem direito à proteção dos interesses morais e materiais que lhe correspondam por motivo das produções científicas, literárias ou artísticas de que seja autora."

Entre nós, está tradicionalmente insculpida em todas as constituições federais, art. 153 da vigente:

“§ 24. A lei assegurará aos autores de inventos industriais privilégio temporário para sua utilização, bem como a propriedade das marcas de indústria e comércio e a exclusividade do nome comercial.

\$ 25. Aos autores de obras literárias, artísticas e científicas pertence o direito exclusivo de utilizá-la. Esse direito é transmissível por herança, pelo tempo que a lei fixar."

De nada, no entanto, valeria proclamar, com tanta solenidade, um compromisso sem traçar as punições correspondentes à sua eventual violação.

Por isso, cominam os arts. 669 a 673 do Código Civil e legislação complementar, normas tendentes a reprimir as mais importantes modalidades de violação dos direitos autorais, merecendo referência específica o art. 672 , que recebeu na Lei n. 5988, de 14.12 .1973 a seguinte redação:

"Art. 123. O autor, cuja obra seja fraudulentamente reproduzida, divulgada ou de qualquer forma utilizada, poderá tanto que o saiba, requerer a apreensão dos exemplares reproduzidos ou a suspensāo da divulgação ou utilização da obra, sem prejuízo do direito à indenização de perdas e danos."

E reiterando, embora com menor amplitude, o que já constava do art. 670 daquele Estatuto, consigna ainda a Lei n. 5988:

“Art. 124. Quem vender, ou expuser à venda, obra reproduzida com fraude, será solidariamente responsável com o contrafator, nos termos dos artigos precedentes; e se a reprodução tiver sido feita no estrangeiro, responderão como contrafatores o importador e o distribuidor."

Revela a experiência que cominações de natureza civil não são suficientes: incluem, por isso, os Códigos Penais na lista das violações, os crimes contra a propriedade intelectual, entre nós reprimidos pelos arts. 184 e 185, nas figuras genérica de violação de direito autoral, e específica de usurpação de nome ou pseudônimo alheio. 
Todavia, as penas aí previstas, respectivamente de detenção de três meses a um ano, ou multa de $\operatorname{Cr} \$ 1,00$ a $\operatorname{Cr} \$ 5,00$, e detenção de seis meses a dois anos, e multa de $\operatorname{Cr} \$ 2,00$ a $\mathrm{Cr} \$ 10,00$, mesmo reajustadas na proporção de 1:2000 pelo art. $4 .^{\circ}$ da Lei n. 6.416, de 24.05.1977, não foram suficientes para intimidar, notando-se, de ano para ano, um extraordinário incremento nessas violações, com clamores cada vez mais generalizados, não só entre nós, como no mundo inteiro.

Procurando adaptar a legislação que se tornara obsoleta aos tempos novos, foi promulgada a Lei n. 6895, de 17.12.1980, que embora sem alterar os valores das penas pecuniárias, agilizou extraordinariamente a ação penal dispensando em inúmeros casos a formalidade da apresentação da queixa, como adiante se verá, e deu ao primeiro dispositivo a seguinte redação:

$$
\begin{aligned}
& \text { "Art. 184. Violar direito autoral: } \\
& \text { Penas - detenção de três meses a um ano, ou } \\
& \text { multa de Cr\$ } 2.000,00 \text { a Cr\$ } 10.000,00 \text {. } \\
& \text { § } 1.0 \text { Se a violação consistir na reprodução, por } \\
& \text { qualquer meio, de obra intelectual, no todo ou em } \\
& \text { parte, para fins de comércio, sem autorização expressa } \\
& \text { do autor ou de quem o represente, ou consistir na } \\
& \text { reprodução de fonograma e videofonograma, sem } \\
& \text { autorização do produtor ou de quem o represente: } \\
& \text { Pena - reclusão de um a quatro anos e multa } \\
& \text { de Cr } \$ 10.000,00 \text { a Cr } \$ 50.000,00 \text {. } \\
& \S 2 .^{\circ} \text {. Na mesma pena do parágrafo anterior } \\
& \text { incorre quem vende, expõe à venda, introduz no País, } \\
& \text { adquire, oculta ou tem em depósito, para o fim de } \\
& \text { venda, original ou cópia de obra intelectual, fono- } \\
& \text { grama ou videofonograma, produzidos com violação de } \\
& \text { direito autoral." }
\end{aligned}
$$

No ofício pelo qual encaminhou o Projeto de Lei ao Presidente da República o respectivo Projeto de Lei, encareceu o Ministro da Justiça IBRAHIM ABI-ACKEL que a iniciativa atendia às normas adotadas pela Convenção Internacional sobre a Proteção de Produtores de Fonogramas contra a Reprodução não autorizada dos mesmos, concluída em Genebra, a 29.10.1971, e promulgada no Brasil, pelo Decreto n. 76.906, de 24.12.1975.

$\mathrm{E}$ frisou que a inclusão de dois parágrafos ao artigo 184, objetivara

\footnotetext{
"tipificar o delito de reprodução, com apenação mais grave, cuja necessidade revelou-se imperiosa, em decorrência das infrações cometidas frontalmente, oriundas de práticas ostensivas, que se tornaram viciosas, consubstanciadas na fixação por qualquer meio, e utilização de obra intelectual, com fins comerciais, não consentida pelo titular do direito, exigindo o interesse público na repressão do crime."
} 


\section{No rol das violações ao direito de autor, o papel desempenhado pela contrafação}

A Consolidação das Leis Penais de Vicente Piragibe continha uma enumeração extensa das diversas figuras que constituem violação dos direitos autorais. $O$ empenho de síntese levou a substituí-la, no texto do art. 184 do Código Penal, pela expressão genérica "violação de direito autoral", compreendendo uma variedade tão ampla de casos, que raros são os autores que se lançam à tentativa de apresentar uma relação completa.

Entre eles, Romeo Grompone, - Presidente da Comissão Jurídica do Conselho Panamericano da Confederação Internacional das Sociedades de Autores e Compositores (CISAC) e Vice-Presidente do Instituto Interamericano do Direito de Autor (IIDA) - , realçando embora a dificuldade da empreitada, teve oportunidade, no Seminário Interamericano de Direitos de Autor, que se reuniu no Panamá em julho de 1980, de apontar os seguintes:

Edição, publicação, venda, execução, representação, por qualquer meio ou instrumento, de uma obra inédita ou publicada, sem autorização prévia do autor, sucessor ou cessionário, ou sociedade autoral que o represente.

Reprodução ou venda de exemplares em maior número do que o autorizado pelo autor, sucessores ou cessionários, ou pela sociedade autoral que o represente.

Adaptação, tradução, paródia, alteração, mutilação ou modificação de uma obra sem o consentimento de autor, seu sucessor ou cessionário, ou sociedade autoral que o represente.

Plágio.

Omissão de mencionar o nome do autor em edições, publicações, execuções ou representações ou a atribuição da autoria a outra pessoa.

Apropriação da letra para uma composição musical ou da música para uma composição escrita, ou de qualquer obra ou fragmento da mesma para sua utilização num filme cinematográfico ou fonograma em geral, ou sua inclusão total ou parcial em outras obras de qualquer índole.

Atribuição indevida da qualidade de autor, sucessor ou cessionário, ou representante deste, com a finalidade de suspender uma representação, irradiação ou execuções públicas ou espetáculos. 
- A anotação indevida, a omissão ou acréscimos de obras ou autores nas planilhas de execução ou representação ou irradiação radiofônica, que devam confeccionar os usuários.

- A reiteração dos ilícitos civis contra o direito de autor.

Com ressalva da paródia, que apenas excepcionalmente, e não como tal, constituirá violação de direito de autor, aditaremos que o Projeto BARBOSA-CHAVES, que serviu amplamente de inspiração à Lei n. 5.988 (não seguido nessa parte), também fez um rol de 16 violações, separando ainda os crimes sujeitos à detenção (art. 161) dos apenados com reclusão (art. 162) :

"Art. 160 - Das violações. Constituem violações ao direito de autor e conexos, da presente lei e das exigências explícita ou implicitamente nela contempladas:

I - Utilizar ou permitir a utilização de qualquer obra protegida, com ou sem intuito de lucro direto ou indireto, sem autorização do titular do direito ou, quando exigida, do CONDAC;

II - Praticar ato contrário ao direito moral do autor, do artista intérprete ou executante;

III - Deixar ou negar-se, àquele a quem incumbe a obrigação, de efetuar ao autor, artista intérprete ou executante, a remuneração ou retribuição devida, na forma e no prazo previsto na presente lei ;

IV - Obter ou receber o participante do produto de arrecadações conjuntas, na utilização do direito de interpretação, execução ou representação, quantia ou valor superior aos percentuais fixados em lei e regulamento;

$\mathrm{V}$ - Deixar de indicar ou omitir, quando obrigatórios, a fonte de origem, dados, indicações ou finalidades da utilização;

VI - Omitir nos exemplares reproduzidos a numeração ou permitir que seja mesmo repetida, ou lacunosa, ou excedente da contagem contratada;

VII - Utilizar obras sujeitas à prévia licença do CONDAC, sem a necessária autorização expressa;

VIII - Deixar de cumprir as determinações do CONDAC ou as obrigações legais para com aquele órgão, ou obstar, por qualquer modo, o exercício das suas finalidades;

IX - Reter, sem prestar contas, na qualidade de representante, quaisquer proventos de utilização dos direitos de autor ou conexos, ou deixar de depositá-los em estabelecimento de crédito, no prazo fixado em lei; 
$\mathrm{X}$ - Deixar ou negar-se a cumprir, quem o deva, as obrigações previstas nesta lei ou obstar ou impedir sejam exercidos os direitos ou faculdades nela assegurados;

XI - Dar causa à resolução ou rescisão do contrato, prejudicando a parte contrária;

XII - Associar-se ou vincular-se a mais de uma sociedade de defesa de direito de autor ou conexos, a não ser em decorrência da diversidade do gênero das obras ou da atividade exercida;

XIII - Deixar ou dificultar os membros dos órgãos diretores e fiscais, funcionários das Sociedades de Defesa dos Direitos de Autor e Conexos ou qualquer servidor público de cumprir as obrigações previstas nesta lei, nas normas estabelecidas pelo CONDAC e disposições complementares;

XIV - Apresentar ou permitir que seja apresentada em público obra sem aprovação do programa prévio ou dele não fazer constar ou não exigir que constem os requisitos estabelecidos pela lei e regulamento;

$\mathrm{XV}$ - Exercer atividade de compositor, artista intérprete ou executante, em prejuízo dos profissionais, na forma do que dispõe o art. 184, parágrafo único;

XVI - Deixar de recolher a contribuição especificada em lei, destinada a órgãos profissionais, na forma do art. 192, $\S \S 10^{\circ}$ e $2 .^{\circ} . "$

A qual dessas figuras poderá no entanto conduzir-se a hipótese mais comum, mais corrente, que reúne o maior número de transgressões e das mais graves, que possam caber dentro desse figurino traçado pelo novo $\S 10^{\circ}$ do art. 184 do Código Penal, quando fala em "reprodução. para fins de comércio, sem autorização expressa" e em "reprodução de fonograma e videofonograma," etc.?

Numa que apenas implicitamente está inscrita nessas enumerações: a contrafação, que, como a palavra indica, é falsificação, imitação fraudulenta, reprodução não autorizada, que constitui ofensa das mais flagrantes do direito de autor, verdadeiro crime de apropriação indébita, violação da propriedade industrial, enriquecimento sem causa e concorrência desleal, flagrantes e indisfarçáveis.

"Recorrendo a manipulações enganadoras" encarece SimoN, reproduzido nas primeiras páginas do Tratado de CHARLES ChenEvard - "o concorrente desonesto não peca somente contra o co-con- 
tratante, ao qual ele vende a sua mercadoria, mas também contra todos os concorrentes lesados pelo seu dolo; ele lança, diz KoHLER, um peso falso na balança das relações de negócios, e obtém assim uma vantagem ilícita sobre aqueles que não tomam como contrapeso senão prestações de um valor real. A perda material ocasionada ao indivíduo por um ato que engana o público em seu conjunto, desaparece em segundo plano na presença do perigo constante que correm a honestidade e a confiança, e que ameaça desmoralizar as relações de negócios e reduzi-las finalmente à impotência."

Para certificar a existência de uma contrafação é suficiente verificar se entre as duas obras existe uma identidade de representação que possa ser reconhecida, isto é, se as duas obras constituam duas representações diferentes e originais, ou se, ao invés, seja uma representação substancialmente única.

É claro que nem toda reprodução constitui necessariamente uma contrafação.

Para que isso ocorra é necessário, ensina J. LABAURIE, L'Usurpation en Matière Littéraire et Artistique, Paris, Boccard, 1919, pág. 48, a concorrência de três elementos, a respeito dos quais discorre extensamente:

$\left.1^{\circ}\right)$ que tenha sido feita sem autorização;

$2 .^{\circ}$ ) que a obra reproduzida não tenha ainda caído no domínio da livre reprodução;

$\left.3 .^{\circ}\right)$ que constitua uma edição, conceito esse que o desenvolvimento da tecnologia fez desprender-se da relação com a edição de livros, para abranger, hoje em dia, toda e qualquer multiplicação de exemplares.

Com a mesma clareza lapidar fixa esse mesmo autor as três condições pelas quais revela a reprodução seu caráter ilícito:

a) uma obra ainda protegida;

b) a falta de autorização;

c) a publicação (págs. 106 e segs.), no caso da nossa lei, a reprodução para fins de comércio.

É o princípio firmado pelo Código Civil:

"Art. 669. Quem publicar obra inédita, ou reproduzir obra em via de publicação ou já publicada, pertencente a outrem, sem outorga ou aquiescência dèste, além de perder, em benefício do autor, ou 


\begin{abstract}
proprietário, os exemplares da reprodução fraudulenta, que se apreenderem, pagar-lhe-á o valor de toda a edição, menos esses exemplares, ao preço por que estiverem ̀̀ venda os genuínos ou em que forem avaliados.

Parágrafo único. Não se conhecendo o número de exemplares fraudulentamente impressos e distribuídos, pagará o transgressor o valor de mil exemplares, além dos apreendidos."
\end{abstract}

\title{
3. Atribuicôes dos Delegados de Polícia em matéria de propriedade imaterial. A aprovação prévia dos programas dos espetáculos públicos remunerados
}

A legislação pátria tem sempre procurado resguardar os direitos dos autores e artistas, intérpretes e executantes por meio de duas providências fundamentais no que diz respeito aos espetáculos públicos: a exigência da aprovação prévia dos programas a serem executados, e a prova de que tais programas são acompanhados, de cada vez, da autorização do titular do direito.

Quanto à primeira, dispunha o Decreto n. 4.790, de 02-01-1924: "Art. 2. ${ }^{\circ}$ - Nenhuma composição musical, tragédia, drama, comédia ou qualquer outra produção, seja qual for a sua denominação, poderá ser executada ou representada em teatros ou espetáculos públicos, para os quais se pague entrada, sem autorização, para cada vez, de seu autor, representante ou pessoa legitimamente sub-rogada nos direitos daquele".

O Decreto n. 5.492, de 16-07-1928 determinou, em seu art. 26, repetido no art. 47 do Decreto 18.527 de 1928, que essa e as disposições seguintes se aplicassem a todas as composições musicais e peças de teatro, executadas, representadas ou transmitidas pela radiotelefonia, com intuito de lucro, em reuniões públicas.

O parágrafo único de cada um desses dispositivos considerou realizadas com intuito de lucro quaisquer audições musicais, representações artísticas ou difusões radiotelefônicas em que os músicos, executantes ou transmitentes, tenham retribuição pelo trabalho, e o art. 27 responsabilizou os proprietários ou empresários de quaisquer estabelecimentos de diversões, salões de concertos ou festivais, pelos direitos autorais das produções aí realizadas.

O Decreto n. 18.527 em seu art. 42, exige, para autorização da representação da obra teatral, aos efeitos da fiscalização dos direitos autorais, a apresentação, para registro, à 
Censura das Casas de Diversões, no Distrito Federal, e da repartição competente nos Estados, do contrato celebrado com o autor.

De conformidade com o art. 43, essas mesmas repartições deverão aprovar previamente o programa de qualquer espetáculo em que se representem peças teatrais de qualquer espécie, ou executem número de canto, bem como - art. 46 - de representações, exibições ou irradiações que se realizem em teatros, cinematógrafos, "dancings", "cabarets", sociedades radiotelefônicas ou outros quaisquer estabelecimentos de diversões públicas.

O Decreto-lei n. 20.493, de 24-01-1946, que aprovou o regulamento do serviço de censura de diversões públicas do Departamento Federal de Segurança Pública, consolidou essas disposições.

A Lei n. 2415, de 09-02-1955 subordinou no art. $10^{\circ}$ a outorga, no território nacional, de licença para a realização de representações, execuções públicas e teletransmissões pelo rádio ou televisão, de que tratam os arts. 42 e 43 , $\S 10^{\circ}$ do Decreto n. 18.527 , de 10-12-1928 e 88 do Decreto n. 20493, de 24-01-1946 exclusivamente ao próprio autor ou a sociedade legalmente constituída para defesa de direitos autorais, à qual o autor é filiado e que o tenha registrado na forma do art. $105, \S 1 .^{\circ}$, do Decreto n. 20.493, de 24-01-1946.

Alterando e revogando dispositivos do regulamento aprovado pelo Decreto n. 18527, de 10-12-1928, o Decreto n. 1023, de 17-05-1962, "para melhor execução de dispositivos constantes dos Decretos ns. 4790 de 02-01-1924 e 5492 de 16-07-1928, especialmente na parte relativa à proteção e fiscalização dos direitos de autor", estendeu aos Estados e Territórios o que já dispunha a legislação em vig:or no Distrito Federal pelo Decreto n. 20.493, de 24-01-1946 que aprovou o Regulamento do Serviço de Censura de Diversões Públicas do Departamento Federal de Segurança Pública:

"Art. 1.'. Qualquer espetáculo público (representaçōes, execuçōes, irradiaçōes, funções esportivas e beneficentes, etc.), realizado em teatro, cinema, estações de rádio e televisão, circo, parque, cassino, clube, associações recreativas ou esportivas, salões de dependências adequadas, depende de aprovação do respectivo programa, pelo Serviço de Censura de Diversões Públicas (S.C.D.P. - hoje Divisão C.D.P.) no Distrito Federal e pela Autoridade policial nos Estados e Territórios, seja o espetáculo ou função promovido por pessoa física ou jurídica, ou por entidade de organização comercial ou de organização civil." 
Coloca o art. $2 .^{\circ}$ (art. 80 do referido Decreto 20493) na expressa dependência dessa condição prévia, "indispensável sob qualquer alegação":

I. As representações de peças teatrais e qualquer espécie, integralmente ou em parte;

II. As representações ou execuções de variedades de qualquer espécie ou gênero, inclusive as que constem de aparelhos mecânicos ;

III. As execuções de números de cantos, música, bailados, peças declamatórias e pantominas;

IV A projeção de filmes cinematográficos;

V. As audições de discos e aparelhos sonor.os em estabelecimentos de diversões públicas ou em quaisquer outros destinados à freqüência coletiva;

VI. As funções e divertimentos quaisquer, realizados em hotéis, restaurantes, dancings, cabarés, cafés-concertos, assim como audições musicais verificadas em estabelecimentos de qualquer gênero, destinadas à freqüência coletiva, com ou sem entrada remunerada;

VII. As funções realizadas em auditórios das estações emissoras radiofônicas e de televisão, seja em suas sedes, ou em qualquer outro local em que se realizem tais funções, com ou sem remuneração, de qualquer maneira, por parte dos assistentes;

VIII. Os espetáculos públicos de qualquer natureza, pagos ou gratuitos, que, embiora não estejam discriminados nos números anteriores, constituem divertimento público.

Não existe o menor fundamento para as incertezas suscitadas sobre a aplicabilidade do referido Decreto n. 1023, uma vez que não está revogado nem expressa nem implicitamente.

Foi, ao contrário, ratificado pela Lei n. 4944, de 06-04-1966, que "Dispõe sobre a proteção a artistas, produtores de fonogramas e organismos de radiodifusão e dá outras providências".

Com efeito o art. 11 e seu parágrafo determinaram a regulamentação da lei pelo Executivo, com inclusão das "disposições dos Decretos ns. 4.790, de 22-01-1924, 5492, de 16-07-1928 e 1023, de 17-05-1962, a ela aplicáveis" o que ocorreu pelo Decreto n. 61.123, de 01-08-1967, que incorporou quase todas as disposições do Decreto n. 1023.

Mais do que confirmado, está pois este transfundido no novo texto. 
Acresce que, se dúvida pudesse persistir, ela foi dirimida por ven. acórdão unânime da Primeira Turma do Supremo Tribunal Federal de 20-06-1972, no rec. extr. n. 74.170, interposto contra decisão do Tribunal de Justiça do Piaú, que negara vigência ao Decreto 1023.

Reconhecendo embora que nem sempre as repartições de polícia contam com pessoal suficiente para exercer suas amplas e múltiplas funções, teve oportunidade o Conselheiro Cláudio DE SouZA AmARAL, em ofício dirigido em data de 27-06-1972 ao sr. Secretário de Segurança Pública do Estado de Goiás, de demonstrar extensamente que por importantíssimas razões de ordem pública, além de conceder a licença para a realização do espetáculo, deve ainda a autoridade policial comparecer ao mesmo com o fim de fiscalizar, verificar e providenciar:

a) se o programa aprovado é o que está sendo executado;

b) no caso de alteração do programa, se o responsável representa ou executa obra que atente contra a moral, os bons costumes e a Segurança Nacional, impedindo no ato o prosseguimento e instaurando a ação criminal cabível;

c) mesmo não ocorrendo a hipótese acima, mas havendo simples alteração do programa, punir o infrator com as medidas administrativas determinadas em lei (Decreto Federal n. 1.023, de 17-05-1962), formando o respectivo processo também administrativo."

Conclui-se que, quem pretenda realizar execução musical dependente de licença autoral é obrigado a apresentar à autoridade competente a relação das obras a serem executadas acompanhada da licença dos respectivos titulares do direito de execução.

Ao princípio da aprovação dos programas, apenas três exceções abre o Decreto n. 1.023, para:

a) as funções de caráter cívico ou educacional, promovidas por entidades oficiais sem nenhum intuito de lucro, sendo apenas necessário que seja feita, antecipadamente, comunicação da realização das mesmas ao S.C.D.P. ou a autoridade policial (art. 11) ;

b) a matéria puramente noticiosa (notas, crônicas, comentários, críticas, etc.). 
c) a matéria comercial (anúncios) dos programas radiofônicos, respondendo cada um pelos abusos que cometer, na forma do art. $1 .^{\circ}$ do Decreto-lei $\mathrm{n}$. 8.556, de 12-12-1945 (art. 14).

Nem mesmo os espetáculos públicos gratuitos, seja qual for sua natureza, inclusive aqueles em que não haja remuneração para os que nele tomam parte, ficam isentos da apresentação de programas, que devem ser acompanhados pela relação completa dos que participarem graciosamente, com as firmas reconhecidas (art. 12 e seu parágrafo).

Complementa o art. 13 que, quando figurarem em programas de qualquer espetáculo, artistas que estejam contratados por empresas de diversões públicas, que não sejam as promotoras desses espetáculos, deve ser exigida a prova, por meio de autorização escrita, de que tais artistas podem tomar parte de dito espetáculo.

A segunda das aludidas providências administrativas fundamentais consiste na complementação da aprovação dos programas com a prova da autorização do titular do direito, proibindo o art. 10 do Decreto n. 1.023, de 1962 (como fazia o Decreto n. 20.493 , de 1946, art. 88), a aprovação de programa de quaisquer audições musicais, representações artísticas ou difusões radiotelefônicas, em casas de diversões ou lugares de reuniões públicas ou coletivas, para os quais se pague entrada, por meio de convites, ou quando constitua atração com intuito de lucro, direta ou indiretamente, sem que os mesmos programas preencham as formalidades legais e venham acompanhadas, cada vez, da autorização do autor ou de pessoa sub-rogada nos direitos deste.

Adita o parágrafo único não dispensar a apresentação de certificados de censura cinematográfica e da prova de autorização do autor ou pessoa sub-rogada.

\section{Colaboração das autoridades policiais com o Ministério do Trabalho}

Determina o art. 93, n. VI do Decreto n. 20.493, de 24-01-1946 apóie o S.C.D.P. as autoridades do Ministério do Trabalho, no que diz respeito às relações trabalhistas entre artistas, auxiliares e demais elementos participantes de espetáculos de diversões públicas com as empresas que operam no ramo. Objetivando o necessário entrosamento e cooperação dos órgãos descentralizados da censura com os Delegados Regionais 
do Trabalho, resolveu o Departamento de Polícia Federal, através de Portaria n. 33, de 16-04-1969, do Serviço de Censura de Diversões Públicas:

“I. Não serão liberados programas e espetáculos de teatro, variedades, circos, buates, produções cinematográficas, radiotelevisão, canto, números musicais, gravações fonográficas e de "video-tape", declamação e congêneres sem que haja contrato de trabalho entre a empresa ou o empresário responsável pela função e os artistas e demais elementos desta participantes.

II. O SCDP e as Turmas de Censura das Delegacias, Subdelegacias e Postos do DPF exigirão dos interessados que façam constar dos requerimentos de censura e de aprovação de programação a relação nominal dos artistas, auxiliares e demais participantes de espetáculos de diversões públicas bem como esclarecimentos relativos aos respectivos contratos de trabalho.

Parágrafo único - Sempre que julgar necessário a autoridade censória exigirá a apresentação do contrato de trabalho do pessoal artístico e técnico participantes de espetáculos de diversões pública.

III. Os órgãos descentralizados da censura farão na ficha de registro referida no item I, art. 94, do Decreto n. 20.493, de 24-1-1946, as anotações necessárias a fim de atualizarem-se e manter o controle da situação empregatória de artistas e técnicos que trabalhem em casas de diversões nas áreas territoriais respectivas."

\section{O novo texto legislativo é de tamanha importância}

A nova redação dada ao parágrafo único do art. 186 do Código Penal, dispensando a queixa na quase totalidade das violações dos direitos de autor, nas reproduções não autorizadas, para fins de comércio, lança, à plena luz da evidência, as atribuições dos Delegados de Polícia, que deixam de ser órgãos passivos, meros expectadores e ordenadores do procedimento, para serem convocados a participar diretamente das atividades processantes, principalmente através da medida fundamental da busca e apreensão.

A contribuição desse importante setor da Administração Pública ficou bem ressaltada no prelúdio do Decreto uruguaio de 21-01-1943, objetivando a adoção de medidas de caráter policial que tendam a proporcionar uma maior garantia dos direitos autorais :

"Considerando: que além de ser boa técnica administrativa proporcionar a utilização, pela autoridade policial, de procedimentos preventivos que resol- 
vam sem violência a respeito dos direitos reconhecidos
por uma Lei da Nação, normas expressas desta atri-
buem à polícia uma função de amparo contra possíveis
violações dos bens protegidos pela referida disposição,
que resulta conveniente regulamentar aos fins de
uma execução adequada da mesma..."

$\mathrm{E}$ antecipando-se justamente nesse sentido, já foi ressaltado, o art. 646 do Projeto do novo Estatuto processual penal, joga à inteira responsabilidade daquelas dignas autoridades, não apenas a nomeação dos dois peritos, como ainda a busca e apreensão de amostras dos instrumentos e do objeto do crime.

O novo texto legislativo é de tamanha importância na evolução da idéia de que não estão mais os titulares dos direitos de autor - nesta década recém-finda das comunisações, assinalada pela conquista dos satélites artificiais, jungidos ao carro de boi das providências legais do começo do século que pode-se dizer constitui um marco definitivo no caminho do aperfeiçoamento das nossas instituições.

Operou verdadeira revolução na repressão penal das violações do direito de autor, aumentando de forma tão extraordinária as atribuições dos nobres componentes da carreira policial que nos grandes centros industriais, comerciais e culturais o razoável cumprimento da determinação legal irá exigir, sem dúvida, a criação, estruturação e devido aparelhamento em homens competentes e material pertinentes, de Delegacias Especializadas. 